\title{
Amino acid content and protein solubility of feather meal as affected by different processing conditions
}

\author{
Manthos C. Papadopoulos (Department of Animal Science, Agricultural Universi- \\ ty, P.O. Box 338, $6700 \mathrm{AH}$ Wageningen, Netherlands)
}

Received 19 September 1984; accepted 13 May 1985

\begin{abstract}
The effect of processing conditions on feather meal protein was studied by multiple regression technique. Changes in amino acid composition, protein in vitro digestibility and solubility due to chemical and enzymatic treatments were investigated. It was concluded that in most cases it is difficult to distinguish the effect of processing on feather meal quality from the corresponding effect on amino acid profile and digestibility in vitro. It is therefore critical that the bioavailability of feather meal protein-amino acids be known.

Key-words: feather meal, amino acids, digestibility in vitro, solubility, processing methods.
\end{abstract}

Introduction. Feather waste at processing plants has been of interest in nutritional studies because of its high protein content. Feather keratin is very rich in the sulphur-containing amino acid cystine. Because the cystine disulphide bonds within the keratin contribute to the indigestibility and insolubility of this keratin, they must be destroyed before feather protein can be digested by animals. While the data support the conclusion that cystine content is reduced by processing treatments such as steam and pressure (Morris \& Balloun, 1973; Wheeler \& Latshaw, 1980), use of chemicals (Wolski et al., 1980) and enzymes (Elmayergi \& Smith; 1971), changes in the other amino acids are not fully understood. Furthermore, comparative studies between untreated feather meals and samples treated with additions of chemicals or enzymes are lacking.

The present study was conducted to investigate in detail the effect of different processing factors, namely time, moisture, added $\mathrm{NaOH}$ or proteolytic enzyme upon amino acid contents and digestibility and solubility of feather meal in vitro.

Materials and methods. Feathers of broiler chicks were treated under three methods: no additions, chemical treatment with $\mathrm{NaOH}(0.2$ to $0.6 \%)$ and enzymatic treatment with a proteolytic enzyme 'maxatase' $(0.2$ to $0.6 \%)$. Autoclaving time and feather moisture content were varied in all three methods from 30 to $70 \mathrm{~min}$ and from 50 to $70 \%$, respectively. A central composite experimental design (Box, 1954) was used to define the different treatment combinations and the data were analysed with multiple regression analysis.

Results and discussion. The results of this investigation showed that the individual amino acids have distinct variations in their response to various processing varia- 
bles (time, moisture, chemicals, enzymes). There are losses, in general, of amino acids during processing of feather meal. This is emphasized by the marked degradation of cystine, which is by far the most heat/alkali-sensitive of the amino acids under prolonged processing conditions, and by smaller losses of the limiting amino acids lysine, methionine and histidine.

The drastic destruction of cystine coincided with the formation of the unusual amino acid lanthionine, suggesting that processing treatments can alter the feather meal protein structure. The amount of lanthionine found approximated the loss of cystine during processing, suggesting that most of the lost cystine is converted to lanthionine.

In general, different processing conditions result in cystine disulphide bond cleavage of feather keratin, thus making the feather protein more soluble and susceptible to digestive proteolytic enzymes.

The present study showed that the digestibility (in pepsin- $\mathrm{HCl}$ solution) and solubility (in alkali or acid solvents) of the test feather meal protein in vitro were increased as result of processing. Because with increasing degree of processing the cystine content is lower and protein in vitro digestibility and solubility values appeared to be higher, it is suggested to use cystine content in the evaluation of feather meal quality as a feedstuff in animal feeding.

Concluding remarks. Feather meal, as a by-product from chicken meat production, is a cheap protein source for animal feeding, rich in several amino acids but deficient in lysine, methionine, histidine and tryptophan. So, it is unsuitable as a single source of amino acids in a diet. The nutritional value of the processed feather meal depends on the losses of amino acids as demonstrated in this investigation and the structural modifications to the protein which are affecting digestibility in vivo of crude protein and amino acids. This is especially critical for the reactive but most frequently limiting essential amino acids lysine, methionine, histidine and tryptophan.

Biological experiments, therefore, are necessary because physico-chemical analyses may not give the actual nutritive value, since not all of each amino acid in a protein is made available to the animal in the course of digestion, absorption and metabolism. This and related factors will be considered in a subsequent communication.

\section{References}

Box, G. E. P., 1954. The exploration and exploitation of response surfaces: Some general considerations and examples. Biometrics 10: 16-60.

Elmayergi, H. H. \& R. E. Smith, 1971. Influence of growth of Streptomyces fradiae on pepsin- $\mathrm{HCl}$ digestibility and methionine content of feather meal. Canadian Journal of Microbiology 17: 1067-1072.

Morris, W. C. \& S. L. Balloun, 1973. Evaluation of five differently processed feather meals by nitrogen retention, net protein values, xanthine dehydrogenase activity and chemical analysis. Poultry Science 52: $1075-1084$.

Wheeler, K. B. \& J. D. Latshaw, 1980. Evaluation of the sulfur amino acid and lanthionine content of feather meal. Poultry Science 59: 1672.

Wolski, T., J. Klimek \& A. Rompala, 1980. Characteristics of modified proteins of keratin in chicken feathers. Acta Alimentaria Polonica 6: 167-172. 
This synopsis is based on part of a doctoral thesis entitled 'Feather meal: evaluation of the effect of processing conditions by chemical and chick assays', Agricultural University, Wageningen, 1984. 139 pp., 17 figs., 32 tables, 7 appendices, 217 refs. English, Dutch summary.

Available as paper copy (order R040P, $f 30$ including postage) or microfiches (order R040M, f 17.50 including postage) at: NARD, clo Pudoc, P.O. Box 4, 6700 AA Wageningen, Netherlands (telex 45015 blhwg nl).

\title{
Biological evaluation of the effect of processing conditions on feather meal amino acid digestibility
}

Manthos C. Papadopoulos (Department of Animal Science, Agricultural University, P.O. Box 338, 6700 AH Wageningen, Netherlands)

Received 19 March 1985; accepted 13 May 1985

\begin{abstract}
Amino acid digestibility determinations by excreta analysis and estimations of ileal and plasma amino acid levels in young chickens proved that processing can affect digestibility of feather meal amino acids to the animal. It was concluded that although ileal and plasma studies may provide useful information on the relative digestibility of dietary feather meal protein, quantitative digestibility measurements by excreta analysis of the individual amino acids have to be used for feather meal quality evaluation.
\end{abstract}

Key-words: feather meal, amino acids, biological digestibility, processing conditions.

Introduction. Feather meal is subjected to various processing treatments to improve its digestibility but the resulting products are not uniform in quality due to variable effects of treatments. Whereas some treatments might increase protein digestibility they could, at the same time, reduce the nutritional value of the dietary proteins by changing the amino acid pattern (Provansal et al., 1975; Hurrell et al., 1976). In a previous communication it was demonstrated that there are losses of amino acids during processing of feather meal especially in cystine (Papadopoulos, 1985). If the digestibility and/or the availability of its amino acids were known, the value of feather meal as a component of animal feeds could be properly assessed.

Literature studies have reported considerable variations in amino acid digestibility between feather meals (Burgos et al., 1974; Bielorai et al., 1983) but factors and conditions causing this variation are hardly quantified. This investigation was con- 